\title{
Test Results of Post-Asst Design Fermilab Built 1.5 Meter, SSC Collider Model Dipole Magnets
}

\author{
T.S. Jaffery, J. Carson, S.W. Delchamps, W. Kinney, W. Koska, M.J. Lamm, \\ J.P. Ozelis, J. Strait, M. Wake \\ Fermi National Accelerator Laboratory \\ P.O. Box 500, Batavia, Illinois 60510
}

September 1992

Presented at the 1992 Applied Superconductivity Conference, Chicago, Illinois, August 23-28, 1992 


\section{Disclaimer}

This report was prepared as an account of work sponsored by an agency of the United States Government. Neither the United States Government nor any agency thereof, nor any of their employees, makes any warranty, express or implied, or assumes any legal liability or responsibility for the accuracy, completeness, or usefulness of any information, apparatus, product, or process disclosed, or represents that its use would not infringe privately owned rights. Reference herein to any specific commercial product, process, or service by trade name, trademark, manufacturer, or otherwise, does not necessarily constitute or imply its endorsement, recommendation, or favoring by the United States Government or any agency thereof. The views and opinions of authors expressed herein do not necessarily state or reflect those of the United States Government or any agency thereof. 


\title{
TEST RESULTS OF POST-ASST DESIGN FERMILAB BUILT 1.5 METER, SSC COLLIDER MODEL DIPOLE MAGNETS
}

\author{
T. S. Jaffery, J. Carson, S.W. Delchamps, W. Kinney, W. Koska, M. J. Lamm, J. P. Ozelis, J. Strait, and M. Wake* \\ Fermi National Accelerator Laboratory \\ Batavia IL. 60510
}

\begin{abstract}
A series of 1.5 meter long and $50 \mathrm{~mm}$ aperture model SSC collider dipole magnets have been successfully built and tested at Fermilab. Later models have been built to test several extensions to the Fermilab design and variations in the manufacturing parameters. Some of the variations tested included conductor insulation scheme, alternate materials for coil end parts and coil winding. The coils are instrumented with voltage taps for the purposes of quench localization and with strain gages to measure the stresses and deflections in the coil and magnets support structure. Data from the quench performance, coil stress, end force and harmonics are presented and compared with design expectations and correlated with changes in the magnet design and assembly methods.
\end{abstract}

\section{INTRODUCTION}

Several 1.5 meter model magnets for the SSC collider dipole, with $50 \mathrm{~mm}$ aperture have been built and tested at Fermilab based on the baseline design Accelerator String System Test (ASST)[1]. Later models were built to test several extensions to the Fermilab design and variations in manufacturing parameters. The test results of "Post-ASST" design model magnets is presented in this paper. The primary purpose of these magnets is to study the effect of different insulation schemes and end part designs on the performance of the magnets. Salient features of these magnets are shown in Table l. To gain experience with this design and to study the performance under cryogenic conditions, five short models and four long $(15 \mathrm{~m})[6]$ dipole magnets have been built. The cable insulation on early models consists of Kapton type $\mathrm{H}$ film and epoxy impregnated glass tape. Later model magnets used Kapton only and its equivalent (Apical) cable insulation films of thickness $0.025 \mathrm{~mm} \times 9.525 \mathrm{~mm}(0.001$ in $\times 0.375 \mathrm{in})$.

End pieces on DSA331-332 are the same as ASST magnets. DSA330 end parts are made with resin transfer molding process (RTM) with glass fiber preform. DSA333 end parts are also RTM and use "B" stage cryorad adhesive and a glass fiber preform. The end sections are supported by collet style aluminum end clamps. The return yoke is vertically split[4]. To achieve the desired prestress the coils were shimmed at the pole using adhesive backed kapton, and wedges were shimmed with brass to make up the difference in cable size due to the difference in cable insulation thickness between ASST and Post-ASST design magnets. Inner coil wedges closest to the parting plane have $0.762 \mathrm{~mm}$ ( $30 \mathrm{mil}$ ) thick brass shim and the other two standard wedges have $0.381 \mathrm{~mm}$ (15 mil) thick brass shim. One piece of $0.076 \mathrm{~mm}$ (3 mil) thick kapton was added between the inner and outer coils to compensate for the radially thinner "kapton only" coils. Quench protection heaters were installed on some magnets. The test results have been reported elsewhere[7].

DSA323B and DSA329B are the reassembled versions of DSA323 and DSA329 respectively with changes shown in Table I. Data are presented for DSA329-332, 323B and 329B. DSA333 had developed a turn-to-turn short during assembly. The shorted inner coil was replaced. DSA333 and 334 have not been cold tested yet. All the magnets were instrumented with 57 voltage taps for quench localization. Strain gage transducers[2] are located in the collars to measure azimuthal stress between the collars and the coils. Four end force gages were used to measure the coil pressure on the end plate due to the differential thermal contraction during the cooldown and the Lorentz force due to the magnet excitation.

TABLE I. Salient Features of Later Model Collider Dipoles Built by Fermilab

1 = Spalding part: 2 = Torlon part; 3 = Cryorad part

\begin{tabular}{|c|c|c|c|}
\hline Magnet & Special Features & $\begin{array}{l}\text { Pole Shim (mm) } \\
\text { Inner/Outer }\end{array}$ & Coil Insulation \\
\hline $\begin{array}{l}323 \\
323 \mathrm{~B}\end{array}$ & $\begin{array}{c}\text { square key } \\
\text { intermediate key }\end{array}$ & $\begin{array}{c}0 / 0 \\
+0.13 /-0.13 \\
\end{array}$ & Kapton H film + epoxy impregnated glass lape \\
\hline $\begin{array}{l}329 \\
329 B\end{array}$ & $\begin{array}{l}\text { 1-Piece keys } \\
\text { 2-Piece keys }\end{array}$ & $\begin{array}{l}+0.09 / 0 \\
+0.09 / 0\end{array}$ & $\begin{array}{l}\text { Kapton } \mathrm{H} \text { film + epoxy impregnated glass tape } \\
\text { and Kapton only on all wedges }\end{array}$ \\
\hline $\begin{array}{l}330 \\
332 \\
333\end{array}$ & $\begin{array}{l}\text { molded keys and saddles } \\
\text { G-10CR same as ASST } \\
\text { molded keys and saddles }{ }^{2}\end{array}$ & $\begin{array}{c}0 /+0.25 \\
0 /+0.51 \\
+0.09 /+0.2\end{array}$ & $\begin{array}{l}\text { all magnets:Kapton with scotch } 2290 \text {; cures at } 135^{\circ} \mathrm{C} \\
\text { In coil=2H+butuLT one side; out coil }=2 \mathrm{H}+2 \mathrm{LT} \text { one side } \\
\text { DSA333 all same except In coils }=2 \mathrm{H}+\text { buttL } \mathrm{T} \text { both side }\end{array}$ \\
\hline $\begin{array}{l}331 \\
334\end{array}$ & $\begin{array}{c}\text { G-10CR end pan } \\
\text { molded keys and saddles }\end{array}$ & $\begin{array}{l}+0.13 / 0 \\
0 /+0.20\end{array}$ & $\begin{array}{l}\text { Apical film with Cryorad adhesive; cures at } 140-155^{\circ} \mathrm{C} \\
\text { In coil }=3 \mathrm{NP}+\text { buttLT one side; out coil }=2 \mathrm{H}+2 \mathrm{~L} \text { T one side } \\
\text { In coil }=2 \mathrm{NP}+\text { buttNP both side; out coil }=2 \mathrm{NP}+2 \mathrm{NP} 1 \text {-side }\end{array}$ \\
\hline
\end{tabular}

Work Supported by the U.S. Department of Energy. Manuscript received on August 24, 1992.

- Present address SSCL, Dallas. Texas, U.S.A. 


\section{EXPERIMENTAL DETAILS}

Tests at liquid helium temperatures were performed in a $3.6 \mathrm{~m}$ vertical dewar in the Fermilab R\&D test facility at Lab2[8]. The strain gages measuring the coil stress and end force were calibrated both at $295 \mathrm{~K}$ and $4.0 \mathrm{~K}$ and therefore measure absolute stress at $4 \mathrm{~K}$. Coil pressures were monitored during the collaring and yoking process and to achieve the correct prestress the coils were shimmed at the pole (Table I) and wedges were shimmed with brass. The desired prestress was achieved on all magnets. The design post yoke prestress for inner / outer coils is $70 \pm 14$ / 56 $\pm 14 \mathrm{MPa}$. The pressures in the coil were also monitored throughout the cooldown and magnet excitation. The prestress loss due to thermal contraction during cooldown are about $35 /-12-15 \mathrm{MPa}$ for inner / outer coils (Table II). These changes are comparable to those in ASST design model magnets[3]. The set screws on magnet ends which transfer the axial load from the coil to the end plate are torqued to achieve a net force of $-4 \mathrm{kN}$ at room temperature. Typically this force increases with cooldown by $-1.4 \mathrm{kN}$ (Table 1), except for DSA 330 where it decreased by 1 $\mathrm{kN}$ as it did for DSA321[3].

\section{MECHANICAL BEHAVIOR}

The average azimuthal coil stress at the pole is plotted as a function of excitation current squared in Fig. 1. Test results show that the pole stress remains positive and there is no sign

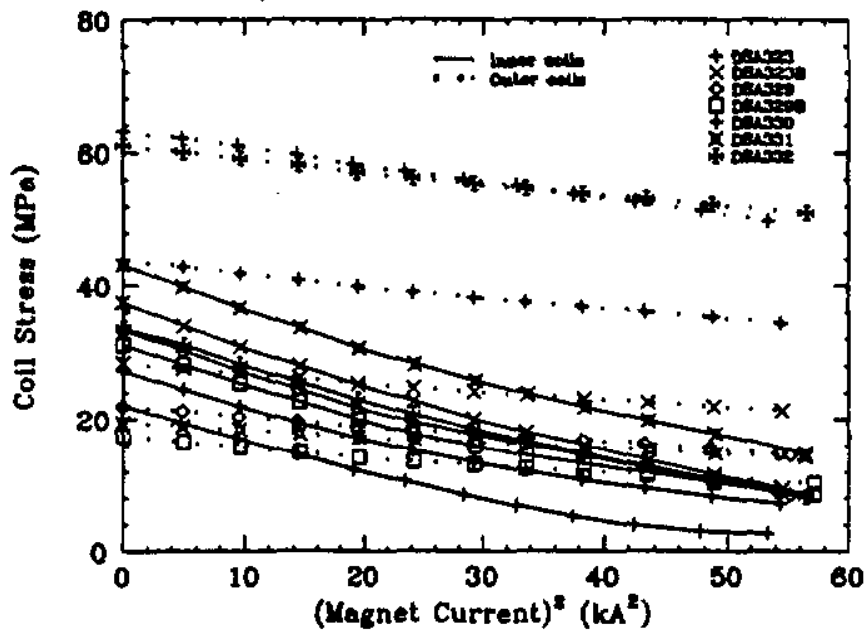

Figure 1: Coil response to magnet current squared $\left(\mathrm{(q}^{2}\right)$.The SSC operating current of $6.6 \mathrm{kA}(6.7 \mathrm{~T})$ is $(44)^{2}$.

Table II. Summary of Coil Prestress For Inner / Outer coils.

\begin{tabular}{|c|c|c|c|c|c|}
\hline Name & $\begin{array}{c}\text { Pre shell } \\
\text { welding } \\
\text { In / out }\end{array}$ & $\begin{array}{c}\text { Post shell } \\
\text { welding } \\
\text { In / out }\end{array}$ & $\begin{array}{c}\text { Warm } \\
\text { In out }\end{array}$ & $\begin{array}{c}\text { After } \\
\text { cooldown } \\
\text { In / out }\end{array}$ & $\begin{array}{c}\text { End force } \\
\text { (kN) } \\
\text { warm/cold }\end{array}$ \\
\hline 3238 & $78 / 35$ & $82 / 40$ & $77 / 38$ & $38 / 29$ & $4.1 / 8.4$ \\
\hline 329 & $74 / 45$ & $79 / 46$ & $68 / 38$ & $34 / 21$ & $4.3 / 5.7$ \\
\hline $329 B$ & $56 / 37$ & $69 / 40$ & $66 / 39$ & $23 / 15$ & $4.9 / 6.3$ \\
\hline 330 & $49 / 64$ & $59 / 67$ & $56 / 63$ & $28 / 47$ & $4.4 / 3.0$ \\
\hline 331 & $84 / 35$ & $89 / 37$ & $80 / 34$ & $44 / 20$ & $5.1 / 6.4$ \\
\hline 332 & $76 / 68$ & $66 / 74$ & $63 / 73$ & $37 / 65$ & $4.3 / 5.9$ \\
\hline
\end{tabular}

of unloading even at $7.5 \mathrm{kA}$. The coil pressure shows a smooth monotonic dependence on the square of the magnet current. Inner coils in DSA323B have higher prestress, than DSA323 and this change eliminated the inner coil unloading at high current observed in DSA323. The outer coil prestress for DSA332 seems considerably higher than it is required. The change in pressure, with excitation, of outer coils of some magnets (e.g. DSA331) is very small as compared to their respective inner coils. This behavior in outer coils can be due to lack of contact between the collar and the yoke in the vertical direction [4]. Pressure changes in inner coils during excitation are correlated to their initial prestresses. As it can be seen in Table II and Fig.l that magnets with higher initial prestress tend to loose more pressure during excitation.

The force measured, by the bullet gages, between the coil end clamp and the end plate, shown in Fig. 2, increases in proportion to current squared. The longitudinal force in the end increases by about $20 \mathrm{kN}$ when the magnet is at $7.5 \mathrm{kA}$, while the total end force is estimated[5] at $3 \mathrm{kN} /(\mathrm{kA})^{2}$. This is a small fraction of the total electro-magnetic force in the coil, as most of the axial force is transferred to the shell through friction between coil and the support structure. Bullet gage preloads changed over thermal cycle in DSA329, 331 and 332 , but it does not seem to change the magnet's quench performance.

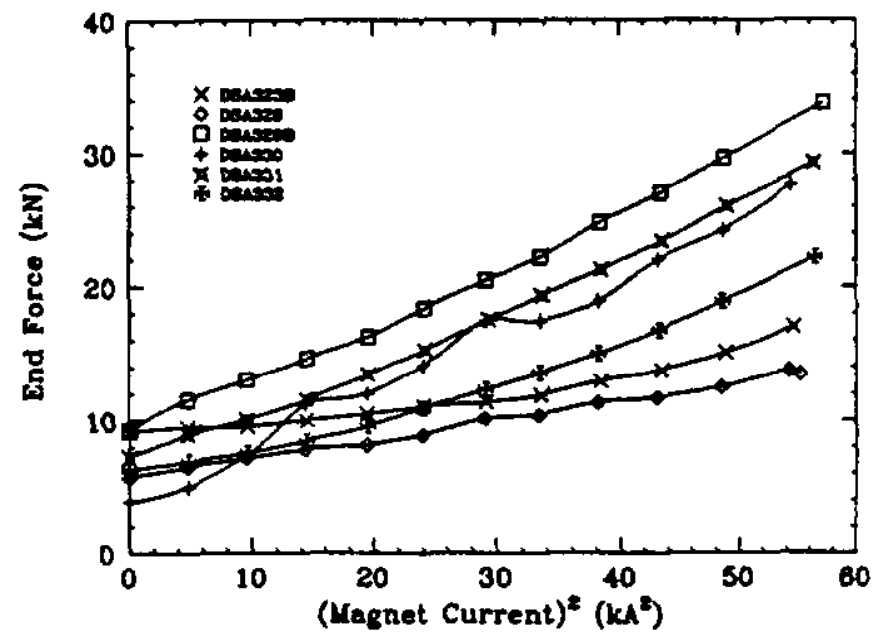

Figure 2: End Force during magnet excitation vs $l^{2}{ }^{2}$

\section{QUENCH PERFORMANCE}

The training and plateau quench (conductor limited quenches) history of all the magnets, at $4.35 \mathrm{~K}$ and $3.8 \mathrm{~K}$, under discussion is shown in Fig. 3. A complete quench history of these magnets at different temperatures $(4.35 \mathrm{~K}, 4.2 \mathrm{~K}$ and $3.8 \mathrm{~K}$ ) has been reported elsewhere [9]. Typically the quench propagation velocity in the straight section of the pole turns of these magnets is $-80 \mathrm{~m} / \mathrm{s}$. For the quenches in Fig. 3 the magnet is ramped at $16 \mathrm{~A} / \mathrm{s}$ from zero excitation current. All, except DSA329 show some training at $4.35 \mathrm{~K}$ and $3.8 \mathrm{~K}$. Most of the training quenches in DSA330-332 and 323B are in the outer coil, which could be due to mechanical motion in the coil. Fist quench in magnets DSA331, 332 and 329B is below the SSC operating current. The first quench in DSA329B (6438 A) is located near the retum end voltage tap, very close to the collet end clamp and the collared part of the coil, near 
the pole end key. Most likely this is due to a design change, in which the pole end key which used to be a single piece, was made into a 2-piece key. Since it can not be ensured that the end key is seated properly during assembly, we suggest that the quench occurs as the key moves into a stable position. Similar behavior was observed in Fermilab built long magnets with 2-piece key[6]. A 2-piece key might aid in assembly but it seems to degrade the magnet's performance. Retraining in some magnets during second themal cycle was also observed which may be due to manufacturing error[9].

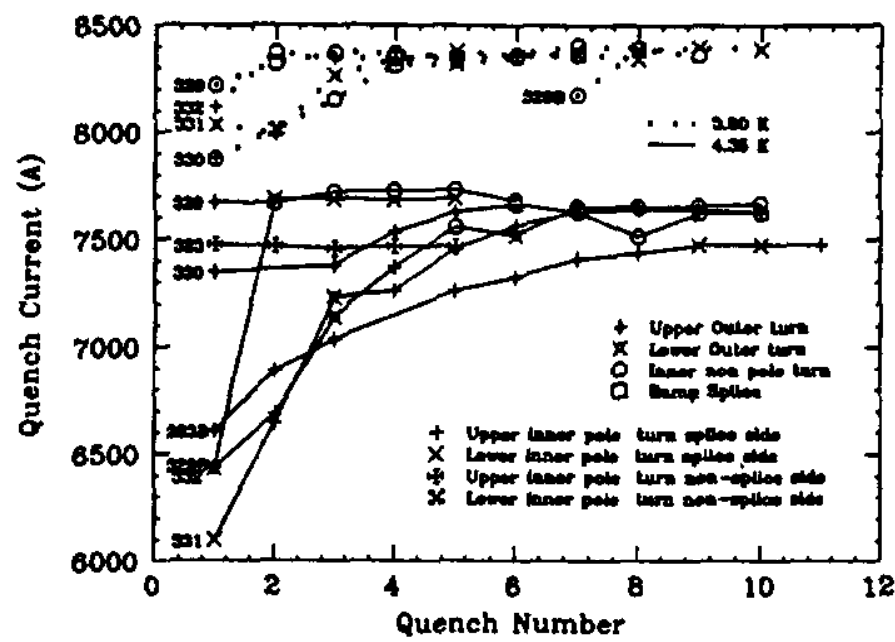

Figure 3: Training History of Quench Current

DSA323 was unkeyed and reassembled as DSA323B with similar pole shims, aluminum end can and collar keying (table I) as DSA324. Since the cable used to wind the DSA323 and 324 coils were from the same reel, one would expect DSA323B to behave in a similar fashion as DSA324. Previously DSA323 quenched on the down ramp after exceeding $7 \mathrm{kA}$ many times without quenching[3]. For DSA323B the average prestress on inner coils was doubled and it was lowered for the outer coils. DSA323B was successfully cold tested without any down ramp quenches. The exact cause of down ramp quenching is not clear. It could be related to either the stainless steel end clamp or lower prestress in the inner coils.

Plateau quenches at $16 \mathrm{~A} / \mathrm{s}$, when the magnet is ramped from zero current to quench, for DSA329.330 and DSA332 are in the non pole turn. When these magnets are ramped close to quench current and held at flattop for a few minutes, then ramped to quench with $\mathrm{d} / \mathrm{dt} \leq 25 \mathrm{~A} / \mathrm{s}$, the quench location changes from non pole turn to pole turn[9]. This is perhaps due to reduced eddy current heating in the coil. For DSA331, 323B and 329B plateau quenches are in the pole tum of the inner coils which is the highest field region. Once the magnets reach plateav, the quench current and location are fairly stable. After the warm-up cycle, magnets DSA331-332 did re-train. DSA330 did not go through second thermal cycle. DSA329 did not show any training at all.

Fig 4 shows the quench current (Iq] as a function of temperature. The temperature dependence of quench current for these magnets is about $18 \% / \mathrm{K}$. Data is not corrected for temperature dependence since temperature variation from quench to quench is within $20-40 \mathrm{mK}$. Lab2 cryogenic temperature monitoring system is good to within $10 \mathrm{mK}[8]$.
The measured difference in plateau quench current $(\Delta \mathrm{Iq})$ is well above the predicted $\Delta \mathrm{lq}$ based on short sample magnet performance, in the normal temperature range $23.8 \mathrm{~K}$. This shows that the magnets have reached the conductor limited quench. DSA329 and DSA329B were quenched at 3.0K as well. The highest quench current on DSA329 at $3.0 \mathrm{~K}$ was $8926 \mathrm{~A}$ at $25 \mathrm{~A} / \mathrm{s}$ and it was still training when testing was stopped.

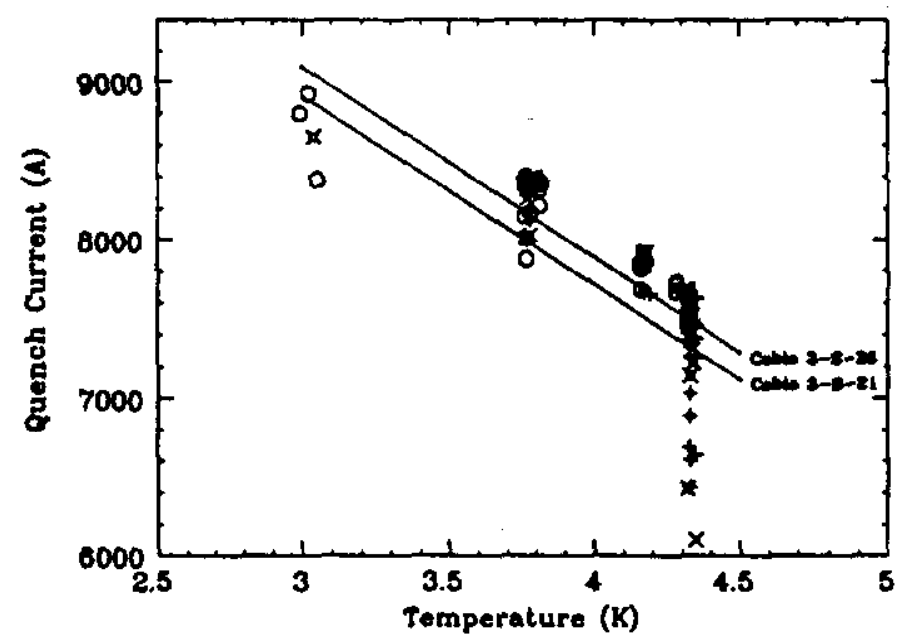

Figure 4: Quench Currents as a function of Temperature, solid lines are predictions based on short sample Ic.

The nominal ramp rate of SSC collider dipole magnet is 4 A/s. For a better understanding of quench behavior, the ramp rate dependence of quench current on these magnets was studied for up $0 \mathrm{dI} / \mathrm{dt}$ of $300 \mathrm{~A} / \mathrm{s}$. Fig. 5 shows the ramp rate dependence of the quench current. For ramp rates $\leq 25 \mathrm{~A} / \mathrm{s}$ the quench current is insensitive to $\mathrm{dI} / \mathrm{dt}$. Difference between DSA323-323B and all the other magnets in Fig.5 is the conductor Ic. $50 \mathrm{~A} / \mathrm{s}$ seems to be a threshold for multiple turn quenches to appear in magnets DSA329-332 and 329B, and all except DSA332 have similar response to high ramp rates. The slope of their $\mathrm{d} l / \mathrm{dt}$ vs Iq are similar for $50-300 \mathrm{~A} / \mathrm{s}$. Whereas this slope for DSA332 is comparable for $50-150 \mathrm{~A} / \mathrm{s}$ and the quench current drops at a much faster rate for ramp rates of $200 \mathrm{~A} / \mathrm{s}$ and above with quenches in the lower outer

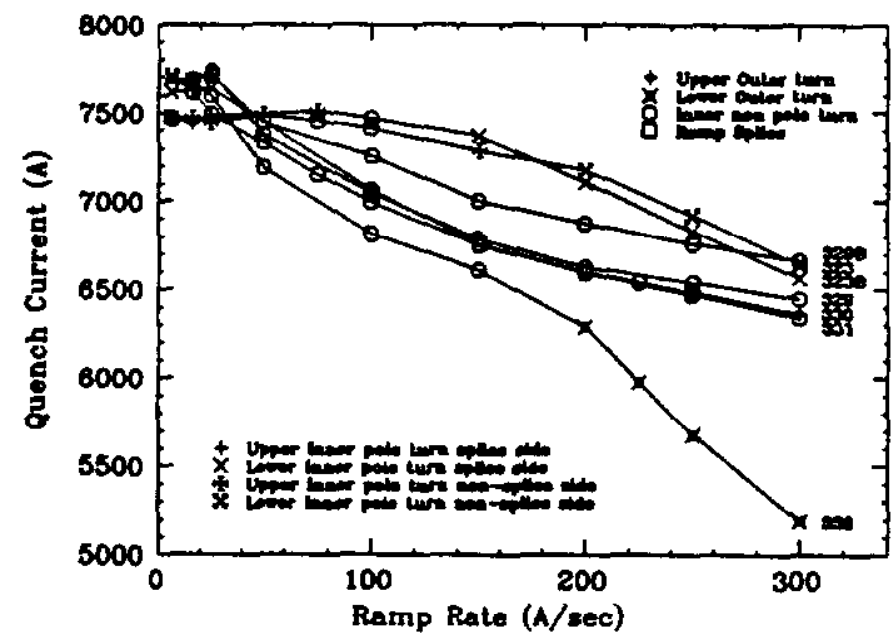

Figure 5: Ramp Rate dependence of Quench Current 
TABLE II. HARMONICS (UNITS @ $10 \mathrm{~mm}$ )

\begin{tabular}{|c|c|c|c|c|}
\hline Pole & 329 & 330 & 331 & 332 \\
\hline b2 Warm & 1.796 & 3.886 & 3.835 & 5.458 \\
\hline Cold & 1.2885 & 3.0985 & 3.3112 & 4.5755 \\
\hline b4 Wam & 0.079 & 0.697 & 0.624 & 0.565 \\
\hline Cold & 0.1039 & 0.6514 & 0.6236 & 0.5686 \\
\hline b6 Wam & -0.037 & 0.045 & 0.049 & 0.026 \\
\hline Cold & -0.0302 & 0.0079 & 0.0327 & -0.0070 \\
\hline b8 Warm & 0.046 & 0.075 & 0.073 & 0.077 \\
\hline Cold & 0.0428 & 0.0621 & 0.0707 & 0.0668 \\
\hline b10 Warm & 0.011 & 0.018 & 0.018 & 0.017 \\
\hline Cold & 0.0147 & 0.0166 & 0.0166 & 0.0166 \\
\hline b1 Warm & -0.467 & 0.224 & 1.015 & -0.517 \\
\hline Cold & -0.0499 & 0.3414 & 1.0118 & -0.3982 \\
\hline b3 Warm & 0.045 & 0.069 & -0.067 & 0.019 \\
\hline Cold & 0.0789 & 0.0178 & -0.0986 & -0.0378 \\
\hline b5 Warm & 0.012 & -0.004 & 0.018 & 0.006 \\
\hline Cold & 0.0036 & 0.0001 & -0.0058 & -0.0021 \\
\hline b7 Warm & 0.001 & 0.000 & 0.000 & 0.000 \\
\hline Cold & 0.0000 & 0.0000 & 0.0000 & 0.0000 \\
\hline b9 Warm & 0.005 & -0.001 & -0.004 & 0.001 \\
\hline Cold & -0.0003 & -0.0033 & 0.0014 & -0.0020 \\
\hline al Warm & -0.666 & 1.235 & -1.028 & 1.237 \\
\hline Cold & -0.5256 & 1.5277 & -1.4446 & 1.1647 \\
\hline a2 Warm & 0.287 & 0.665 & 1.093 & 0.221 \\
\hline Cold & 0.3099 & 0.7755 & 0.9372 & -0.0011 \\
\hline a3 Warm & -0.039 & -0.010 & -0.060 & 0.090 \\
\hline Cold & -0.0642 & -0.0796 & -0.1145 & 0.0319 \\
\hline a4 Warm & 0.040 & 0.050 & -0.029 & 0.010 \\
\hline Cold & -0.0228 & -0.0134 & -0.0649 & -0.0301 \\
\hline 86 Warm & 0.010 & 0.003 & -0.001 & -0.001 \\
\hline Cold & -0.0050 & -0.0165 & -0.0030 & -0.0070 \\
\hline & & & & \\
\hline TF Warm & 1.041 & 1.040 & 1.041 & 1.042 \\
\hline TF Cold & 1.044 & 1.043 & 1.044 & 1.046 \\
\hline & & & & \\
\hline & & & \\
\hline
\end{tabular}

coil. For magnets with higher sensitivity to high ramp rate, quenches originated in the midturns (near copper wedge) which happens to be a less instrumented part of the magnet. Midtum quenches could be due to eddy current heating in the wedge. Eddy currents in the multitum section is higher than the pole turn, since the field direction is most perpendicular to the wide cable face. A good correlation exists between the ramp rate dependence of the quench current and the eddy current losses. The difference in the ramp rate dependence may result from variations in the energy losses due to eddy current[10].

\section{MAGNETIC FIELD MEASUREMENTS}

Magnetic field measurements are made at different stages of the production and cold testing of magnets. Table 3 summarizes the field measurements at room temperature and at $4.2 \mathrm{~K}$ in boiling helium at 1 atmosphere. Measured transfer function of the warm and cold assembled magnets with prediction[1] are also given in Table III. Some of the measured harmonics are not included in Table III. The cold and warm harmonics data in Table 3 is at the same longitudinal positions in the magnet. Room temperature measurements were made at $\pm 10 \mathrm{~A}$ and then average was taken $\omega$ eliminate the effect of earth's magnetic filed. Harmonics for DSA323B and 329B were not measured.

The cold measurements are an average of magnetic field measured at 2kA from the up and down ramp cycle which exceeds a current of $7 \mathrm{kA}$. For cold measurements the probe is positioned longitudinally $-22 \mathrm{~cm}$ away from the strain gage pack, since gage pack becomes magnetic when the magnet is excited at cryogenic temperatures, thus contributing significantly to b2 and b4 when the magnet is at $2 \mathrm{kA}$. There is a good correlation between warm and cold harmonics.

\section{CONCLUSION}

DSA323B test results show that unusual phenomenon like down ramp quenching of a magnet can be avoided by adequate coil prestress and proper assembly of a magnet.

A two-piece pole end key may facilitate magnet assembly but it seems to degrade the magnet's performance, as we have seen on $15 \mathrm{~m}$ long Fermilab dipoles[6] and DSA329B.

Post-ASST design magnets need to be studied more to fully understand their behavior. DSA333 and 334 results will be presented when they are available.

We would like to acknowledge the work of many engineers and technicians whose efforts made possible the results presented in this paper.

\section{REFERENCES}

[1] E.G. Pewitt ed. "50 mm Collider Dipole Magnet Requirements and Specifications" Fermilab 16 Aug 1991.

[2] C.L. Goodzeit, "Measurements of Internal Forces in Superconducting Accelerator Magnets with Strain Gauge transducers", IEEE Trans. Magn. 25:1463 (1989).

[3] J. Strait, et al.. "Mechanical Behavior of Fermilab built $1.5 \mathrm{~m}$ Model SSC Collider Dipoles" EEE Trans. on Magn. 28:137, Jan 1992.

[4] J. Strait et al: "Mechanical Design of 2D Cross-section of the SSC Collider Dipole Magnet", submitted to IEEE Particle Accelerator Conference, San Francisco, CA, May 6-9 1991.

[5] M. Wake, et al., "Test of 1.5 meter Model $50 \mathrm{~mm}$ SSC Collider Dipoles", submitted to IEEE Particle Accelerator Conference, San Francisco,CA, May 6-9 1991.

[6] J. Kuzminski et al; "Quench Performance of $50 \mathrm{~mm}, 15 \mathrm{~m}$ Long SSC Dipole Magnets Built at Fermilab" XVth International Conference on High Energy Accelerators, Germany, July 20-24,1992.

[7] T. Jaffery "DSA332 Heater Test Results" Fermilab Internal Technical Note TS-SSC-92 070.

[8] M.J. Lamm et al; "A Facility to Test Short Superconducting Accelerator Magnets at Fermilab" LOD. 6 this conference.

[9] T. Jaffery "Test Results of Post ASST design Model Magnets " Fermilab internal Tech. Note TS-SSC 92-076.

[10] J.P.Ozelis et al; "AC Loss Measurement of Model and Full Size 50mm SSC Collider Magnets at Fermilab " LOA-9 this conference. 